\title{
Science Academies' Refresher Course in Plant Taxonomy
}

\author{
at \\ Department of Biology, \\ The Gandhigram Rural Institute (Deemed to be University), Dindigul, Tamil Nadu
}

12 December - 26 December 2018

\author{
Sponsored by \\ Indian Academy of Sciences, Bengaluru \\ Indian National Science Academy, New Delhi \\ The National Academy of Sciences, India, Allahabad
}

\begin{abstract}
Plant taxonomy is the science deals with identification, description and nomenclature of plants and their classification into different groups according to the resemblance and differences mainly by their morphological characters. The weakness of taxonomic and systematic skills in the region is recognized as a serious handicap for the efficient inventory, monitoring and management of biological resources and conservation of Biological diversity. Considering the increasing demand for more trained taxonomists and to address the issues of biodiversity documentation, conservation, monitoring and management, it is crucial to conduct training on Plant Taxonomy. The Refresher Course on Plant taxonomy offers a general training on classical and modern aspects of Plant taxonomic and nomenclatural research including exercises in the morphological analysis of living plants, herbarium preparation, documentation etc. A variety of teaching methods like lectures, discussions and fieldwork focusing on diverse aspects will be used and it will facilitate research and teaching programmes for young teachers. The Course will also help the young botanists to gain and sharpen their skills in Plant taxonomy. The skills thus gained will help them to become better teacher cum researchers.
\end{abstract}

Applications are invited from eligible teachers with experience in teaching undergraduate and postgraduate courses in Botany. Maximum of 35 applications will be considered and teachers who wish to participate in the Refresher Course may apply through proper channel with the following details: name, date of birth, gender, e-mail, official and residential addresses, contact mobile phone numbers, academic qualifications, courses taught, affiliation, positions held and tenure. It is also essential to submit a brief statement (between 250 and 500 words) as to why they think the Course will help to improve their classroom teaching of Plant Taxonomy. Applications should be submitted ONLINE by clicking the following link:

http://web-japps.ias.ac.in: 8080/Refreshcourse/PGRI.jsp

A printed copy of the application approved by the Head of the institution stating that leave will be sanctioned if the applicant is selected for the Course should be sent by speed post to: $\mathrm{Dr}$ R Ramasubbu, Coordinator, Science Academies' Refresher Course, Department of Biology, The Gandhigram Rural Institute (Deemed to be University), Dindigul-624302. The candidates will be provided local hospitality and round trip bus/train (three-tier AC) fare by the shortest route. Please note that participants have to attend the full duration of the Course.

Course Director: Dr M Sanjappa, INSA Senior Scientist, Mahatma Gandhi Botanical Garden, University of Agricultural Sciences, GKVK, Bengaluru 560065 Course Coordinator: Dr R Ramasubbu, Coordinator, Science Academies' Refresher Course, Department of Biology, The Gandhigram Rural Institute (Deemed to be University), Dindigul 624302. Mob: 9488591719; Email: racprabha@gmail.com

\section{Last date for the receipt of applications: 1 December 2018}

Selected participants will be informed by: 3 December 2018 